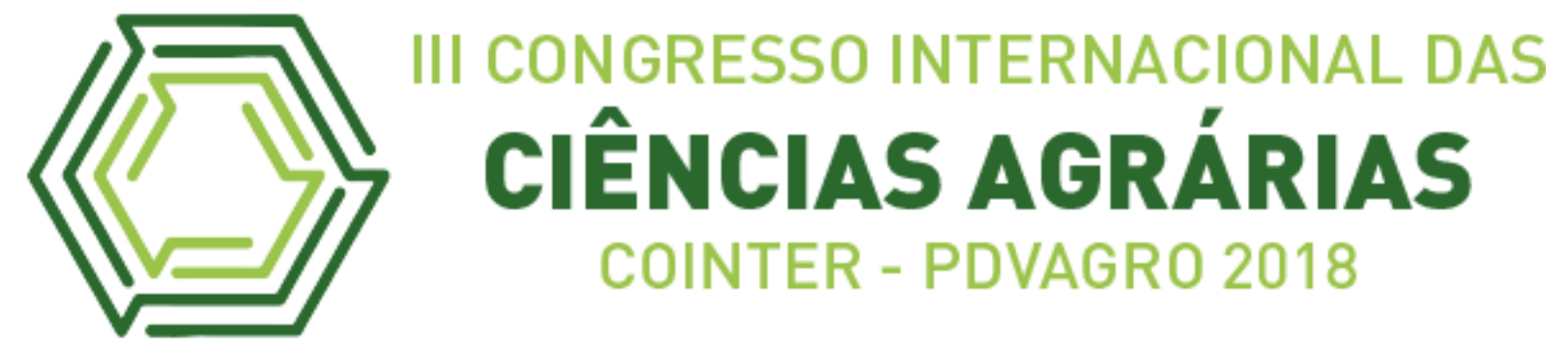

\title{
ESCORE DE LESÕES EM MATRIZES SUÍNAS ALOJADAS EM BAIAS COLETIVAS
}

\author{
Apresentação: Pôster
}

Juliana Camilo da Silva ${ }^{1}$; Jacqueline dos Santos Neves ${ }^{2}$; Ewerson Santos de Oliveira ${ }^{3}$; Cesar Augusto Pospssil Garbossa ${ }^{4}$; Maria de Fátima Araújo Vieira ${ }^{5}$

\section{DOI: https://doi.org/10.31692/2526-7701.IIICOINTERPDVAGRO.2018.00466}

\section{Introdução}

A carne suína é hoje a mais consumida mundialmente, o que impulsiona, cada vez mais, o crescimento do setor. O Brasil tem acompanhado esse crescimento, e hoje ocupa o $4^{\circ}$ lugar no mundo em produção e exportação de suínos, tendo produzido 11,6 milhões de toneladas de carne em 2017, e exportado, no mesmo ano, 697 mil toneladas (ABPA, 2018).

O crescimento da suinocultura se deu, além de outros fatores, pela intensificação do setor produtivo e a criação dos animais em sistemas intensivos de confinamento. No entanto, esses sistemas refletem em mudanças comportamentais e, em alguns casos, aumento no nível de estresse aos quais os animais estão submetidos (BAPTISTA et al., 2011).

O alojamento de matrizes suínas em baias coletivas possibilita a expressão do comportamento natural das mesmas, no entanto, aumentam as interações agressivas entre fêmeas, resultando em lesões de pele e, consequentemente, influenciando negativamente no desempenho reprodutivo destas (FERREIRA et al., 2014). Ainda de acordo com o mesmo autor, as interações agressivas são mais expressivas quando não há um fornecimento da dieta individual.

Diante do exposto, fica evidente a necessidade de se estudar mais as interações agressivas entre matrizes suínas gestantes e assim, propor estratégias de manejo que minimizem o impacto destas questões sobre a produtividade. Dessa forma, objetivou-se

\footnotetext{
${ }^{1}$ Zootecnia, Universidade Federal Rural da Amazônia-UFRA, julianacamilo.s@outlook.com

${ }^{2}$ Zootecnia, Universidade Federal Rural da Amazônia-UFRA, jacquelinesneves2016@gmail.com

${ }^{3}$ Zootecnia, Universidade Federal Rural da Amazônia-UFRA, ewerson.96.oliveira@gmail.com

${ }^{4}$ Professor; Universidade de São Paulo, Pirassununga-SP, cgarbossa@hotmail.com

${ }^{5}$ Orientadora; Doutora, Universidade Federal Rural da Amazônia-UFRA, fatimaraujo.vieira@gmail.com
} 
avaliar o escore de lesões de pele apresentadas por matrizes suínas em gestação coletiva submetidas à diferentes sistemas de arraçoamento.

\section{Fundamentação Teórica}

Stevens et al., (2015), aborda em pesquisa que no estágio inicial do estabelecimento e formação dos lotes de matrizes suínas para as baias coletivas deve-se haver maior atenção dos manejadores, em relação aos demais períodos da fase da gestação, por ocorrer inúmeras agressões devido às disputas por espaço, água e ração até que se estabeleça a hierarquia, podendo ser um período que ocasione maiores números de lesões.

O uso de baias coletivas na gestação, principalmente com sistemas de fornecimento de ração automático, são empregados com o objetivo de beneficiar o bem-estar animal, contudo, essa estrutura favorece a aparição de lesões corporais e de membros locomotores que podem reduzir o ganho de peso e o desempenho reprodutivo das matrizes (CUNHA, 2015).

Com base no exposto, o conteúdo abordado possui a finalidade avaliar a incidência e escore de lesões em matrizes suínas alojadas em baias coletivas de diferentes sistemas de arraçoamento.

\section{Metodologia}

O experimento foi conduzido em granja suinícola de ciclo completo, localizada no município de Paragominas-PA, e encontra-se de acordo com as normas do Conselho Nacional de Controle da Experimentação Animal (CONCEA), sendo aprovada pela comissão de ética no uso de animais da Universidade Federal Rural da Amazônia, sob o nº 065/2016 (CEUA) e 23084.019038/2016-44 (UFRA).

Foram avaliadas 30 fêmeas suínas gestantes (hiperprolíferas), alojadas em baias coletivas com diferentes sistemas de arraçoamento, distribuídas da seguinte forma: 15 porcas alojadas em baia com sistema de arraçoamento semiautomático tipo DROP (SSA) alimentador em linha, na qual a ração é fornecida uma vez ao dia, e as outras 15 em baia com sistema de alimentação automática CallMatic 2 da Big Ducthman (SA), no qual o consumo é controlado através do software, proporcionando uma dieta individualizada à cada matriz.

Realizou-se a avaliação de lesões de pele por observação direta aos 5, 55 e 105 dias de gestação. Foram atribuídas pontuações de 0 a 2, diferenciadas por legenda que caracterizam o grau das injúrias, sendo zero para matrizes sem lesões de pele, um para aquelas que 
apresentavam lesões moderadas e dois às matrizes com lesões graves. Os dados foram analisados por meio de estatística descritiva.

\section{Resultados e Discussão}

A avaliação do escore de lesões de pele como medição indireta de comportamentos destrutivos e agressivos das porcas mantidas em baias com diferentes sistemas de arraçoamento, são mostrados na tabela 1.

Tabela 1- Avaliação de lesões de pele de matrizes suínas em gestação coletiva com diferentes sistemas de fornecimento de ração. Paragominas-PA. Fonte: Própria.

\begin{tabular}{ccc}
\hline Escore & $\begin{array}{c}\text { Sistema semiautomático } \\
\text { de alimentação (\%) }\end{array}$ & $\begin{array}{c}\text { Sistema Automático de } \\
\text { alimentação (\%) }\end{array}$ \\
Sem lesão (0) & $\mathbf{5}$ dias de gestação & 13,33 \\
Lesão moderada (1) & 6,67 & 46,67 \\
Lesão grave (2) & 53,33 & 40 \\
& 40 & \\
Sem lesão (0) & $\mathbf{5 5}$ dias de gestação & 26,66 \\
Lesão moderada (1) & 33,33 & 66,67 \\
Lesão grave (2) & 66,67 & 6,67 \\
& 0 & 66,67 \\
Sem lesão (0) & $\mathbf{1 0 5}$ dias de gestação & 20 \\
Lesão moderada (1) & 14,29 & 13,33 \\
Lesão grave (2) & 78,57 & \\
Sem lesão (0) & 7,14 & 35,56 \\
Lesão moderada (1) & Média do período total (\%) & 44,44 \\
Lesão grave (2) & 18,09 & 20 \\
\hline
\end{tabular}

A baia com sistema automatizado de alimentação (SA) apresentou maior número de matrizes sem injúrias $(35,56 \%)$ durante o período gestacional quando comparadas as matrizes do tratamento com sistema semiautomático de alimentação (SSA) $(18,09 \%)$.

As lesões moderadas (escore 1), que são aquelas caracterizadas por perdas de pelo, calos, arranhões e/ou vermelhidão foram observadas em um maior número percentual de porcas pertencentes à baia com sistema semiautomático de alimentação (média do período total- SSA: $66,19 \%$ e SA: $44,44 \%)$. 
Possivelmente o que explica tais resultados é o fato da baia SSA dispor a ração num sistema tipo DROP e apenas uma vez ao dia, havendo falta de individualidade no comedouro e assim possibilitando mais disputas por espaço e por alimento, o que gera brigas e consequentemente lesões nos animais.

Scheneider et al., (2007), estudando matrizes gestantes alimentadas com diferentes frequências ao dia, porém em quantidade semelhante de ração, observaram que porcas alimentavas 2 vezes/dia apresentaram mais lesões de pele $(\mathrm{P}<0,01)$ que porcas alimentadas 6 vezes/dia. Assim, uma alternativa para diminuir as interações agressivas é aumentar o número de arraçoamento ao dia na tentativa de minimizar a agressividade entre os animais da baia.

A perfeita condição corporal de matrizes reprodutoras torna-se fundamental para o desempenho reprodutivo das mesmas, já que matrizes sem lesões e em ambientes tranquilos vivem mais e produzem mais (MERCHIOR, 2012).

O tratamento que dispõe de sistema automático de fornecimento de ração possibilitando uma atividade de alimentação individual, não garante, no entanto, a isenção de lesões nas matrizes. De acordo com Cunha (2015), e o observado no estudo, um fato que explica a permanência de lesões graves em animais alojados em baias com sistema automático de alimentação, está relacionado as agressões localizadas no local de entrada da estação de alimentação, como observado na classificação de lesão grave (escore 2), onde a baia com estação automática apresentou maior porcentagem de porcas com feridas abertas consideradas injúrias mais severas, com $20 \%$ dos animais observados com esta categoria de lesão.

Observa-se que independente dos tratamentos, há um maior percentual de porcas com lesões moderadas e lesões graves na fase inicial de gestação do que nas demais fases, o que pode ser explicado pelo fato de, no período entre 3 a 25 dias, existe uma maior possibilidade de ocorrer comportamentos agressivos no qual geram lesões para fêmeas alojadas em baias coletivas (KARLEN et al., 2007).

Segundo Panzardi (2011), as brigas entres os suínos acontecem, dentre outros fatores, com o objetivo de estabelecer grupos sociais e a formação de hierarquia, sendo, portanto, mais intensas nos primeiros dias de alojamento das baias, podendo acarretar em prejuízos na reprodução, como abortos logo no início da gestação.

De acordo com Melchior et al., (2012) outro fator que pode influenciar no 
aparecimento de lesões é o tipo de construção das baias experimentais. Na granja onde realizou-se o estudo, as baias são de concreto, configurando laterais e piso ásperos, o que pode ter influenciado no número de porcas com lesões do tipo moderada nos dois tratamentos, devido a fricção da pele dos animais nas paredes e piso. Assim para minimizar esse tipo de lesão, é importante atentar-se a construção adequada das baias e a correta manutenção dos pisos evitando problemas reprodutivos e o descarte precoce das matrizes reprodutoras.

\section{Conclusões}

As baias coletivas com fornecimento automático de alimentação apresentam menor número de animais sem lesões de pele, porém o sistema de alojamento em baias coletivas, não garante o bem-estar adequado de matrizes suínas gestantes.

\section{Referências}

ABPA - Associação Brasileira de Proteína Animal. Relatório Anual. 2018.

BAPTISTA, R.I.A.A.; BERTANI, G.R.; BARBOSA, C.N. Indicadores do bem-estar em suínos. Ciência Rural, Santa Maria, v. 41, n. 10, p. 1823-1830, 2011.

CUNHA, E. C. P, 2015. Avaliação de diferentes sistemas de alojamento durante a gestação de leitoas nas lesões, desempenho reprodutivo e peso dos leitões ao nascer. Dissertação de mestrado, Universidade Federal do Rio Grande do Sul, Faculdade de Veterinária, programa de pós-graduação em ciências Veterinárias.

FERREIRA, A. H.; CARRARO, B.; DALLANORA, D.; MACHADO, G.; MACHADO, I. P.; PINHEIRO, R.; ROHR, S. Produção de Suínos: Terias e Práticas. $1^{a}$ ed. Brasília; ABCS, p. 23, 2014.

KARLEN G.A.M, HEMSWORTH P.H, GONYOU H.W, FABREGA E, STROM A.D, SMITS R.J. The welfare of gestating sows in conventional stalls and large groups on deep litter. Applied Animal Behaviour Science 105, p. 87-101, 2007.

MELCHIOR R., ZANELLA I., ALBERTO LOVATTO P., ROBERTA LEHNEN C., LANFERDINI E., ANDRETTA I. Meta-analysis on the relationship among feeding characteristics, salivary and plasmatic cortisol levels, and performance of pregnant sows housed in different systems. Livestock Science, pp. 310-315, 2012.

PANZARDI, A., MELLAGI, A.P.G., BIERHALS, T., GHELLER, N.B., BERNARDI, M.L., BORTOLOZZO, F.P., WENTZ, I. Ganho de peso de porcas gestantes associado ao comportamento em baias e à uniformidade da leitegada. Pesquisa Agropecuária Brasileira., Brasília, V.46, n.11, p. 1562-1569, 2011. 
SCHNEIDER, J. D.; M. D. TOKACH, M.D; DRITZ, S.S.; NELSSEN, J.L.; DE ROUCHEY,J.M.; GOODBAND R.D. Effects of feeding schedule on body condition, aggressiveness, and reproductive failure in group-housed sows. Journal of Animal Science, v. 85, p- 3462-3469, 2007.

STEVENS B., KARLEN G.M., MORRISON R., GONYOU H.W., BUTLER K.L., KERSWELL K.J., HEMSWORTH P.H. Effects of stage of gestation at mixing on aggression, injuries and stress in sows. Applied Animal Behaviour Science, 165, p. 40-46. 2015. 